\title{
Pressure dependent isotopic fractionation in the photolysis of formaldehyde-d $d_{2}$
}

\author{
E. J. K. Nilsson ${ }^{1}$, J. A. Schmidt ${ }^{2}$, and M. S. Johnson ${ }^{2}$ \\ ${ }^{1}$ Division of Combustion Physics, Department of Physics, Lund University, P.O. Box 118, 22100 Lund, Sweden \\ ${ }^{2}$ Department of Chemistry, University of Copenhagen, Universitetsparken 5, 2100 Copenhagen $\varnothing$, Denmark
}

Correspondence to: E. J. K. Nilsson (elna.heimdal_nilsson@forbrf.lth.se)

Received: 11 February 2013 - Published in Atmos. Chem. Phys. Discuss.: 19 April 2013

Revised: 27 November 2013 - Accepted: 10 December 2013 - Published: 20 January 2014

\begin{abstract}
The isotope effects in formaldehyde photolysis are the key link between the $\delta \mathrm{D}$ of methane emissions and the $\delta \mathrm{D}$ of atmospheric in situ hydrogen production. A few recent studies have suggested that a pressure dependence in the isotopic fractionation can partly explain enrichment of deuterium with altitude in the atmosphere. The mechanism and the extent of this pressure dependency is, however, not adequately described. In the present work $\mathrm{D}_{2} \mathrm{CO}$ and $\mathrm{H}_{2} \mathrm{CO}$ were photolyzed in a static reaction chamber at bath gas pressures of 50, 200, 400, 600 and 1000 mbar; these experiments compliment and extend our earlier work with $\mathrm{HDCO}$ vs. $\mathrm{H}_{2} \mathrm{CO}$. The UV lamps used for photolysis emit light at wavelengths that primarily dissociate formaldehyde into molecular products, $\mathrm{CO}$ and $\mathrm{H}_{2}$ or $\mathrm{D}_{2}$. The isotope effect $k\left(\mathrm{H}_{2} \mathrm{CO}\right) / k\left(\mathrm{D}_{2} \mathrm{CO}\right)=3.16 \pm 0.03$ at $1000 \mathrm{mbar}$ is in good agreement with results from previous studies. Similarly to what was previously shown for $k\left(\mathrm{H}_{2} \mathrm{CO}\right) / k(\mathrm{HDCO})$, the isotope effect decreased as pressure decreased. In addition, a model was constructed using RRKM theory to calculate the lifetime of excited formaldehyde on the $S_{0}$ surface, to investigate its role in the observed pressure dependent photolytic fractionation of deuterium. The model shows that part of the fractionation is a result of competition between the isotopologue dependent rates of unimolecular dissociation and collisional relaxation. We suggest that the remaining fractionation is due to isotope effects in the rate of the non-radiative transition from $S_{1}$ to $S_{0}$, which are not considered in the present model.
\end{abstract}

\section{Introduction}

Formaldehyde is a key intermediate in hydrocarbon oxidation and plays a central role in both atmospheric and combustion chemistry. It enters the atmosphere as a primary emission from combustion engines and biomass burning, and is also formed in the atmosphere, mainly as a result of $\mathrm{OH}$ initiated oxidation of methane and larger hydrocarbons. Being a reactive species and an important part of both natural and anthropogenic atmospheric chemistry, the reaction sequences where formaldehyde is an intermediate have consequences for regional air quality and global atmospheric composition (Seinfeld and Pandis, 1998).

As an example of the importance of formaldehyde, over half of atmospheric $\mathrm{H}_{2}$ is produced by formaldehyde photolysis. The global budget of $\mathrm{H}_{2}$ has recently been reviewed and modeled (Ehhalt and Rohrer, 2009; Pieterse et al., 2011). An accurate chemical mechanism describing the formation and loss of formaldehyde is necessary to the function and utility of such models. Isotopic composition is an additional observable used to constrain species budgets and atmospheric models. This approach requires information about the isotopic composition of different sources of the compounds, and of isotopic fractionation in production and loss processes (Brenninkmeijer et al., 2003). Normal formaldehyde, $\mathrm{H}_{2} \mathrm{CO}$, is the main species, while $\mathrm{H}_{2}{ }^{13} \mathrm{CO}$ is the most common of the minor isotopologues, followed by $\mathrm{H}_{2} \mathrm{C}^{18} \mathrm{O}$ and $\mathrm{H}_{2} \mathrm{C}^{17} \mathrm{O}$ (Johnson et al., 2002). Monodeutero formaldehyde, HDCO, has recieved increasing attention, as deuterium abundance is a useful tracer in the carbon and hydrogen cycles (Pieterse et al., 2011; Nilsson et al., 2007; Feilberg et al., 2007b, 2005a). While dideutero formaldehyde, $\mathrm{D}_{2} \mathrm{CO}$, is of minor 
Table 1. Summary of previous experimental results for isotope effects, $k\left(\mathrm{H}_{2} \mathrm{CO}\right) / k(\mathrm{XDCO})(\mathrm{X}=\mathrm{H}$ or $\mathrm{D})$, of deuterated formaldehyde at atmospheric pressure, and the results obtained at 1000 mbar in the present study.

\begin{tabular}{lcccccl}
\hline Experimental facility & Volume & Light source & Total & Molecular & Radical & Reference \\
\hline HDCO: & & & & & & \\
EUPHORE & $200 \mathrm{~m}^{3}$ & Sunlight & $1.58 \pm 0.03$ & $1.82 \pm 0.07$ & $1.1 \pm 0.06$ & Feilberg et al. (2007b) \\
Glass/quartz vessel & $1-3 \mathrm{~L}$ & Sunlight & $2.50 \pm 0.03$ & $2.00 \pm 0.02$ & $4.5 \pm 0.08$ & Rhee et al. (2008) \\
SAPHIRE & $370 \mathrm{~m}^{3}$ & Sunlight & $1.63 \pm 0.03$ & $1.63 \pm 0.03$ & - & Röckmann et al. (2010) \\
Quartz chamber & $101 \mathrm{~L}$ & UVA & $1.75 \pm 0.1$ & - & - & Nilsson et al. (2010) \\
\hline $\mathrm{D}_{2}$ CO: & & & & & \\
EUPHORE & $200 \mathrm{~m}^{3}$ & Sunlight & $3.00 \pm 0.50$ & - & - & Feilberg et al. (2005b, 2007a) \\
EUPHORE & $200 \mathrm{~m}^{3}$ & Sunlight & $3.15 \pm 0.08$ & - & - & Nilsson et al. (2009a) \\
Quartz chamber & $101 \mathrm{~L}$ & UVA & $3.16 \pm 0.03$ & - & - & This work \\
\hline
\end{tabular}

importance in the atmosphere due to its low abundance compared with the other isotopologues, studies of isotopically substituted analogs are frequently used to investigate mechanism, reaction kinetics and dynamics.

The major source of formaldehyde in the atmosphere, methane, is depleted in deuterium, while molecular hydrogen from formaldehyde photolysis is strongly enriched (Gerst and Quay, 2001). It has been shown that there is a large deuterium enrichment in the formation of formaldehyde from the monodeuterated methoxy radical (Nilsson et al., 2010; Hu et al., 2012). The kinetic isotope effects in the photolysis of formaldehyde under ambient conditions, for HDCO as well as $\mathrm{D}_{2} \mathrm{CO}$, have been determined in several studies summarized in Table 1. For an evaluation of the HDCO results we refer to the discussion in Nilsson et al. (2010). The kinetic isotope effects for photolysis of dideutero formaldehyde have been determined in two studies at the European Photoreactor Facility (Feilberg et al., 2005b, 2007a; Nilsson et al., 2009a); the results are in reasonable agreement and are presented in Table 1 .

Modeling studies seem to show altitude dependent deuterium fractionation in the photochemical source of molecular hydrogen (i.e., formaldehyde photolysis) (Röckmann et al., 2003; Mar et al., 2007; Pieterse et al., 2011); measurements show increasing deuterium enrichment with altitude (Röckmann et al., 2003; Mar et al., 2007; Batenburg et al., 2012). A pressure dependent isotope effect for monodeutero formaldehyde was demonstrated in a recent publication by our group (Nilsson et al., 2010). This pressure dependence can explain all or part of the altitude dependent deuterium enrichment; part of the altiude dependence may also arise from wavelength dependence. Pressure dependence has been implemented in version 5.0 of a global transport model (TM5) (Krol et al., 2005; Pieterse et al., 2011), the first global model with an explicit isotope reaction scheme for photochemical production of $\mathrm{H}_{2}$. Pieterse et al. (2011) show that they can obtain agreement between modeled and measured atmospheric isotopic composition by varying relevant isotopic parameters within their uncertainty ranges, but note that the available data are not sufficient to constrain the isotope budget uniquely. They conclude that further work is needed to determine isotopic fractionation quantitatively in the methane oxidation chain.

Photolysis of formaldehyde has two channels giving molecular products $\mathrm{H}_{2}+\mathrm{CO}$ and radical products $\mathrm{H}+\mathrm{HCO}$. Experiments show that there is a pressure dependence in the quantum yield for the molecular channel; this dependence has been parameterized by Sander et al. (2006). No pressure dependence is observed in the radical channel. The molecular channel (R1) has a threshold energy at a wavelength of about $360 \mathrm{~nm}$, while the radical channel (R2) has a threshold in the region 330-340 nm (Troe, 2007; Sander et al., 2006). A portion of the molecular products form via the "roaming atom" mechanism (R3) (Bowman and Zhang, 2006; Townsend et al., 2004)

$$
\begin{aligned}
& \mathrm{H}_{2} \mathrm{CO}+h v \rightarrow \mathrm{H}_{2}+\mathrm{CO}, \\
& \mathrm{H}_{2} \mathrm{CO}+h v \rightarrow \mathrm{H}+\mathrm{HCO}, \\
& \mathrm{H}_{2} \mathrm{CO}+h v \rightarrow \mathrm{H} \cdot \mathrm{HCO} \rightarrow \mathrm{H}_{2}+\mathrm{CO} .
\end{aligned}
$$

The photodissociation process has been investigated using experimental and theoretical methods, as outlined by Troe (2007), Herath and Suits (2011) and Lahankar et al. (2007). The molecular channel photodissociation occurs in three steps. First the system is excited from the ground state $\left(S_{0}\right)$ to the first excited singlet state $\left(S_{1}\right)$,

$\mathrm{H}_{2} \mathrm{CO}\left(S_{0}, J\right)+h v \rightarrow \mathrm{H}_{2} \mathrm{CO}^{*}\left(S_{1}, J^{\prime}\right)$,

where the total angular momentum, $J$, is subject to the selection rule,

$\Delta J=J-J^{\prime}=0, \pm 1$.

Secondly, from $S_{1}$, the system undergoes a radiationless transition to $S_{0}$, and finally forms products via unimolecular dissociation,

$\mathrm{H}_{2} \mathrm{CO}^{*}\left(S_{1}, J^{\prime}\right) \rightarrow \mathrm{H}_{2} \mathrm{CO}^{*}\left(S_{0}, J^{\prime}\right) \rightarrow \mathrm{H}_{2}+\mathrm{CO}$. 
Dissociation into the molecular channel competes with quenching via bath gas collision, and, at energies above the radical channel threshold, Reaction (R2). The extent of the contribution from the "roaming" pathway, Reaction (R3), is not fully understood and contributes around $1 / 3$ of the molecular channel, depending on excitation energy (Herath and Suits, 2011; Lahankar et al., 2007). Several publications present RRKM theory applied to photolysis of formaldehyde to give molecular products (Gray et al., 1981; Troe, 2007).

The main aim of the present work is to investigate experimentally the pressure dependence in the isotope effects in photolysis of dideutero formaldehyde. The study was carried out in the same way as the previously published study on HDCO (Nilsson et al., 2010). The unimolecular lifetime of excited formaldehyde on the $S_{0}$ surface was investigated using an RRKM model to characterize the mechanism and pressure dependence of deuterium fractionation in $\mathrm{H}_{2} \mathrm{CO}$, $\mathrm{HDCO}$ and $\mathrm{D}_{2} \mathrm{CO}$ photolysis under the present experimental conditions.

\section{Experimental}

The photolysis experiments were carried out in a $2 \mathrm{~m}$-long quartz chamber with a volume of $101.4 \mathrm{~L}$, surrounded by 8 UVA lamps with emission maximum at $350 \mathrm{~nm}$, emission spectrum shown in Fig. 1. The setup is enclosed in insulated, temperature-controlled housing; for this study the temperature was kept at $293 \pm 0.5 \mathrm{~K}$. Loss of reactants was monitored using a Bruker IFS66v/s FTIR spectrometer coupled to a White type optical system in the reaction chamber. The absorption path length was $72 \mathrm{~m}$ and a liquid nitrogen cooled InSb detector was used. For further details on the experimental setup we refer to Nilsson et al. (2009b).

The relative photolysis rate of $\mathrm{H}_{2} \mathrm{CO}$ versus $\mathrm{D}_{2} \mathrm{CO}$ was determined at total pressures of 50,200, 400, 600 and 1000 mbar, using synthetic air (Air Liquide) as bath gas. The experiments were performed in the same way as in our study of the pressure dependence of the monodeuterated formaldehyde isotopologue described in Nilsson et al. (2010).

Initial partial pressures of formaldehyde isotopologues for each experiment are given in the third and fourth column of Table 2. FTIR spectra were analyzed using the spectral fitting program MALT510 (Griffith, 1996). The experimental spectra were analyzed for the formaldehyde isotopologues, and in cases of overlapping absorptions, $\mathrm{H}_{2} \mathrm{O}, \mathrm{HDO}$ and $\mathrm{CO}$ were also included in the analysis. For the formaldehyde isotopologues high-resolution reference spectra by Gratien et al. (2007) were used as input for the spectral fitting at $600 \mathrm{mbar}$ and $1000 \mathrm{mbar}$ total pressure. At lower pressures reference spectra were taken in the same reaction chamber under conditions identical to those of the experiments. High-resolution line parameters from the HITRAN database were used for $\mathrm{H}_{2} \mathrm{O}$, HDO and CO (Rothman et al., 2009). The program MALT510 calculates best-fit values for concentrations of the

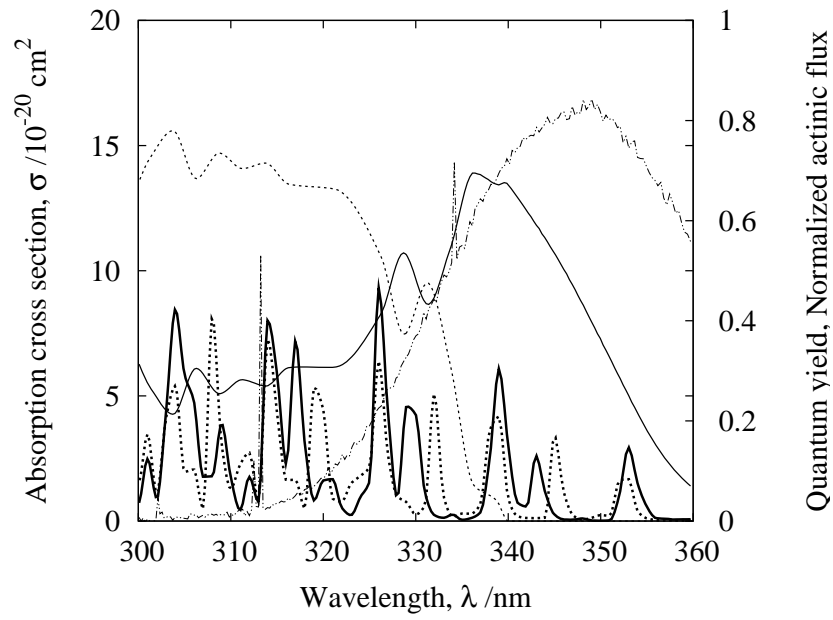

Fig. 1. Absorption cross sections of $\mathrm{H}_{2} \mathrm{CO}$ (thick full drawn line) and $\mathrm{D}_{2} \mathrm{CO}$ (thick dashed line) from Gratien et al. (2007). Also shown are the quantum yield at 1013 mbar in the molecular channel (full drawn line), the quantum yield in the radical channel (dashed line) (Atkinson et al., 2006), and the emission spectrum of the Osram Eversun 100W/79 photolysis lamp (dash-dotted line).

Table 2. Experimental relative rates, $k\left(\mathrm{H}_{2} \mathrm{CO}\right) / k\left(\mathrm{D}_{2} \mathrm{CO}\right)$, at different chamber pressures and the initial partial pressures of the two isotopologues.

\begin{tabular}{lccc}
\hline $\begin{array}{l}\text { Pressure } \\
\text { mbar }\end{array}$ & $k\left(\mathrm{H}_{2} \mathrm{CO}\right) / k\left(\mathrm{D}_{2} \mathrm{CO}\right)$ & $\begin{array}{c}{\left[\mathrm{H}_{2} \mathrm{CO}\right]_{0}} \\
\mu \mathrm{bar}\end{array}$ & $\begin{array}{c}{\left[\mathrm{D}_{2} \mathrm{CO}\right]_{0}} \\
\mu b a r\end{array}$ \\
\hline 50 & $1.17 \pm 0.02$ & 2.2 & 0.76 \\
50 & $1.13 \pm 0.05$ & 1.6 & 0.52 \\
200 & $1.68 \pm 0.03$ & 3.9 & 2.4 \\
200 & $1.78 \pm 0.04$ & 7.8 & 2.9 \\
400 & $2.18 \pm 0.06$ & 3.8 & 2.6 \\
600 & $2.24 \pm 0.04$ & 8.5 & 4.7 \\
600 & $2.33 \pm 0.05$ & 9.6 & 3.2 \\
1000 & $3.16 \pm 0.03$ & 15.1 & 5.7 \\
\hline
\end{tabular}

specified species and their standard errors, for further information see Griffith (1996). The size of the errors calculated by the program are dependent on the quality and resolution of the experimental spectra and reference spectra, and the occurence of spectral overlap with other species. In the present study the typical error in the spectral fit was lower than $0.5 \%$ for $\mathrm{H}_{2} \mathrm{CO}$ concentrations and up to $1 \%$ for the deuterated isotopologue. The natural logarithms of the relative concentrations were plotted for each experiment, as shown in Fig. 2; error bars from the analysis of IR spectra using MALT510 are included. The relative reaction rates given in the second column of Table 2 were obtained by a linear regression to the data points shown in Fig. 2; uncertainties in concentration were included in the regression. 


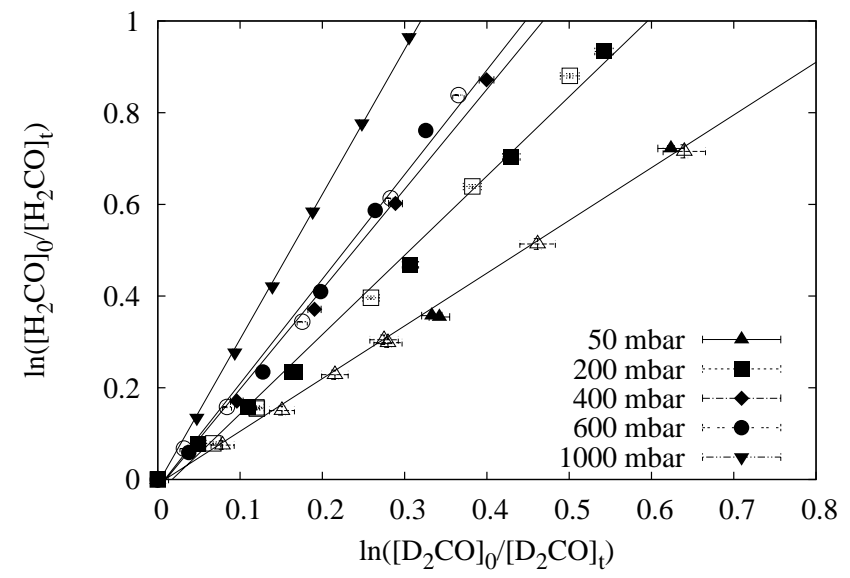

Fig. 2. Relative rate plots of $\mathrm{H}_{2} \mathrm{CO}$ vs. $\mathrm{D}_{2} \mathrm{CO}$ at the different pressures; closed and open symbols at pressures 50, 200 and 600 mbar represent different experiments.

\section{Calculations}

\subsection{Quantum chemistry calculations}

The relevant minima and transition states of the $\mathrm{H}_{2} \mathrm{CO}$ electronic ground state were located using the geometry optimization program in Molpro 2010 (?) using the Singles Doubles with perturbed triples Coupled Cluster (CCSD(T)) methodology (Knowles et al., 1993, 2000; Watts et al., 1993; Deegan and Knowles, 1994) and the aug-cc-pVQZ orbital basis set (Dunning, 1989; Woon and Dunning, 1993). The vibrational frequencies at the stationary points were computed using the same level of theory for all isotopologues, $\mathrm{H}_{2} \mathrm{CO}$, HDCO and DHCO (not equivalent at the non-symmetrical transition state), and $\mathrm{D}_{2} \mathrm{CO}$. The electronic energies were refined using the aug-cc-pV5Z orbital basis set. The correlation energy was then extrapolated to the complete basis set limit using the formula of Halkier et al. (1998). The barrier height and vibrational frequencies for $\mathrm{H}_{2} \mathrm{CO}$ are in good agreement with the theoretical results of Bowman and Zhang (2006). Energies of the stationary points, vibrational frequencies and zero point energies are available as supporting material.

\subsection{Rate calculations}

A model was constructed to determine the isotopic fractionation occurring in the competition between unimolecular dissociation and collisional quenching. The rate of dissociation into the molecular channel, $k_{\mathrm{dis}}\left(E_{\mathrm{ph}}\right)$, upon absorbing a photon of energy, $E_{\mathrm{ph}}$, can then, within RRKM theory (Wardlaw and Marcus, 1988; Billing and Mikkelsen, 1996), be written as

$k_{\mathrm{dis}}\left(E_{\mathrm{ph}}\right)=\sum_{J} k_{\mathrm{dis}}^{\mathrm{rot}}\left(E_{\mathrm{ph}}, J\right)(2 J+1) e^{-E_{J} / k T}$.

We assume that a molecule in the $J$ 'th state has an equal probability of being excited into the $(J-1), J$ and $(J+1)$ 'th

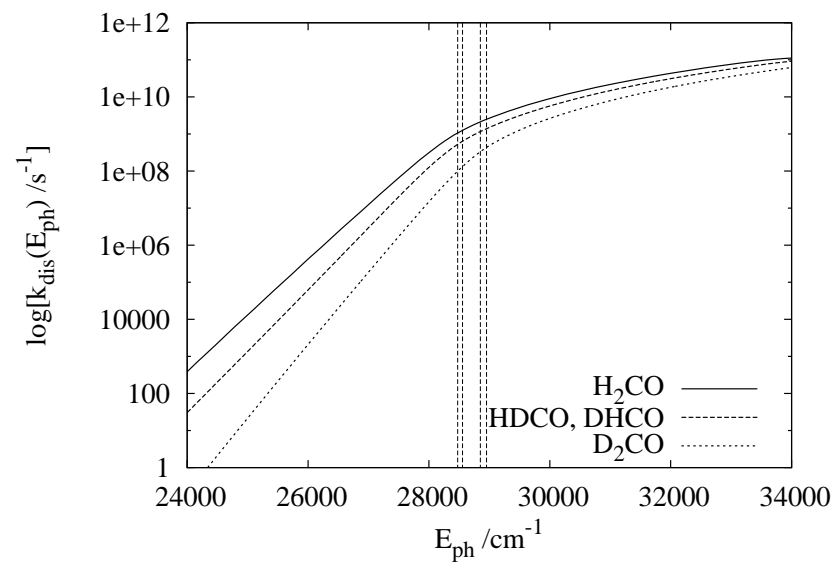

Fig. 3. Dissociation rate as a function of photon energy at $T=300 \mathrm{~K}$. The vertical lines mark the position of the barrier for dissociation; $28460 \mathrm{~cm}^{-1}\left(\mathrm{H}_{2}-\mathrm{CO}\right), 28538 \mathrm{~cm}^{-1}$ (HD-CO), $28839 \mathrm{~cm}^{-1}(\mathrm{DH}-\mathrm{CO})$ and $28940 \mathrm{~cm}^{-1}\left(\mathrm{D}_{2}-\mathrm{CO}\right)$.

state. $k_{\mathrm{dis}}^{\mathrm{rot}}\left(E_{\mathrm{ph}}, J\right)$ is then given by

$k_{\mathrm{dis}}^{\mathrm{rot}}\left(E_{\mathrm{ph}}, J\right)=\frac{1}{3} \sum_{J^{\prime}=J-1}^{J+1} k_{\mathrm{uni}}\left(E_{\mathrm{ph}}, J^{\prime}\right)$,

where $k_{\mathrm{uni}}\left(E_{\mathrm{ph}}, J\right)$ is the unimolecular (i.e., RRKM) rate constant

$k_{\text {uni }}\left(E_{\mathrm{ph}}, J\right)=\frac{N^{\mathrm{TS}}\left(E_{\mathrm{ph}}, J\right)}{h \rho\left(E_{\mathrm{ph}}, J\right)}$.

Here $N^{\mathrm{TS}}(E, J)$ is the sum of states at the transition state leading to dissociation and $\rho(E, J)$ is the adduct density of states. $N^{\mathrm{TS}}(E, J)$ and $\rho(E, J)$ were evaluated by direct count using the extended Beyer-Swinehart algorithm (Stein and Rabinovitch, 1973) and including Eckart barrier tunneling corrections as described by Miller (1979). The dissociation rates for the different isotopes of formaldehyde are shown in Fig. 3. For $\mathrm{H}_{2} \mathrm{CO}$ and $\mathrm{D}_{2} \mathrm{CO}$ there are two equivalent dissociation channels, while for HDCO the two channels are different.

Unimolecular dissociation competes with relaxation via bath gas collision. The quantum yield for going into the molecular channel is therefore dependent on pressure and can be approximated as

$Y_{\mathrm{mol}}\left(E_{\mathrm{ph}}\right)=\left(1-Y_{\mathrm{rad}}\left(E_{\mathrm{ph}}\right)\right) \frac{k_{\mathrm{dis}}\left(E_{\mathrm{ph}}\right)}{k_{\mathrm{dis}}\left(E_{\mathrm{ph}}\right)+k_{\text {relax }}[M]}$,

where $k_{\text {relax }}$, within the strong collision assumption, is the bimolecular collision rate, and $Y_{\text {rad }}$ is the quantum yield for dissociation into the radical channel (see Fig. 1). Figure 5 shows quantum yields in the molecular channel in the range of pressures studied in the present work; as the pressure decreases the bath gas collisions become less important for quenching excited formaldehyde molecules, resulting in a yield approaching unity. 
Once the molecular channel quantum yield is known, the overall rate for production of $\mathrm{H}_{2}+\mathrm{CO}$ can be calculated as

$j_{\mathrm{mol}}=\int \mathrm{d} E_{\mathrm{ph}} \sigma\left(E_{\mathrm{ph}}\right) I\left(E_{\mathrm{ph}}\right) Y_{\mathrm{mol}}\left(E_{\mathrm{ph}}\right)$,

where $I\left(E_{\mathrm{ph}}\right)$ is the spectrum of light available for photolysis and $\sigma\left(E_{p h}\right)$ is the absorption cross section of formaldehyde (see Fig. 1). In a similar manner the rate of dissociation in the radical channel can be calculated as

$j_{\mathrm{rad}}=\int \mathrm{d} E_{\mathrm{ph}} \sigma\left(E_{\mathrm{ph}}\right) I\left(E_{\mathrm{ph}}\right) Y_{\mathrm{rad}}\left(E_{\mathrm{ph}}\right)$.

The total rate of dissociation can be calculated as the sum of the two component terms. The isotope effect is calculated from the total rate.

The rate calculations were performed using the STATRATE program package, previously used for calculations concerning pressure dependence in the isotope effects in the OCS + OH reaction (Schmidt et al., 2012).

\section{Results}

Relative reaction rates $k\left(\mathrm{H}_{2} \mathrm{CO}\right) / k\left(\mathrm{D}_{2} \mathrm{CO}\right)$ determined in each experiment are presented in Table 2 and Fig. 2. These quantities are the rates of photodissociation for the present experimental conditions, inferred from the loss of the two isotopologues throughout the experiments. The photolysis lamps are chosen primarily to photolyze formaldehyde at wavelengths resulting in molecular products. The error bars shown in Fig. 2 are the errors on concentrations of the isotopologues, obtained in the spectral fitting procedure. There are possibly other experimental uncertainties and errors resulting from the fitting procedure, adding several percent errors and thus explaining the scatter in the results at a given pressure.

In the present work and in Nilsson et al. (2010), our goal has been to establish the pressure dependence of the isotope effect in the molecular channel. Due to the constraints of our experiments, so far it has not been possible to examine the wavelength dependence of the isotopic fractionation; to date we know no good evidence for or against the existence of such an effect.

An upward curvature can be seen in some of the data in Fig. 2, in particular at the intermediate pressures. This could possibly be a result of secondary chemistry removing the reactants, but this is unlikely since the effect is not seen at the highest and lowest pressures. The curvature is more likely to depend on errors in the spectral fitting procedure.

As can be seen in Fig. 1 there is a tail of the lamp emission spectrum at wavelengths giving radical products. This effect is discussed in the study on HDCO (Nilsson et al., 2010). In sum, the experimental results can be corrected for photolysis into radical products to yield the isotopic fractionation in the molecular channel; the approach relies on experimental data

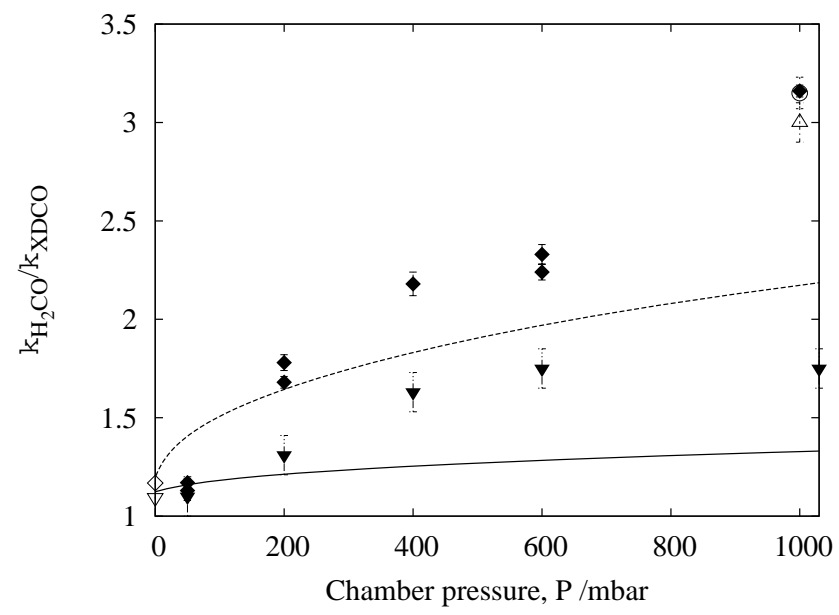

Fig. 4. Relative dissociation rate of formaldehyde $k\left(\mathrm{H}_{2} \mathrm{CO}\right) / k(\mathrm{XDCO}) \quad(\mathrm{X}=\mathrm{H}$ or $\mathrm{D})$ as a function of pressure. The diamonds are the same data as presented in Table 2. Closed triangles represent the corresponding values for the HDCO isotopologue, from Nilsson et al. (2010). Open symbols are previous determinations of $k\left(\mathrm{H}_{2} \mathrm{CO}\right) / k\left(\mathrm{D}_{2} \mathrm{CO}\right)$ from Feilberg et al. $(2005 \mathrm{~b}$, 2007a), triangle, and Nilsson et al. (2009a), circle. Lines represent the calculated isotope effects.

for the quantum yields. The available data sets for radical channel quantum yield in the wavelength region of interest (Sander et al., 2006; Atkinson et al., 2006; Troe, 2007) are unfortunately not in good enough agreement to allow a wellconstrained parameterization. Also, there is no data available on how isotopic substitution affects the quantum yield; such an effect is likely to be larger for $\mathrm{D}_{2} \mathrm{CO}$ than for HDCO. Another complication is uncertainty regarding the isotope effect in the radical channel. Previous determinations disagree for HDCO (Feilberg et al., 2007b; Rhee et al., 2008). No data on the radical channel isotope effect exists for $\mathrm{D}_{2} \mathrm{CO}$. In our previous work (Nilsson et al., 2010) the sensitivity of a parameterization to the different literature values for absorption cross sections and radical channel isotopic fractionation are discussed in detail.

In Fig. 4 the relative removal rates are plotted as a function of chamber pressure, including the atmospheric pressure results from the studies at the European Photoreaction Facility (Feilberg et al., 2005b, 2007a; Nilsson et al., 2009a), and the results from the study on HDCO (Nilsson et al., 2010). The present results at 1000 mbar are in agreement with the results from the previous studies, an agreement that was also seen for the HDCO isotopologue (Nilsson et al., 2010). The isotope effect ranges from about 1.1 at a chamber pressure of 50 mbar, up to about 3 at 1000 mbar. This means that at the lowest pressures the isotope effect for $\mathrm{D}_{2} \mathrm{CO}$ is similar to that of HDCO, while at higher pressures the difference is about a factor of two. From Fig. 4 it is seen that in the case of HDCO the ratio $k\left(\mathrm{H}_{2} \mathrm{CO}\right) / k(\mathrm{HDCO})$ levels out in the region 400 600 mbar; additional pressure increase does not increase the 


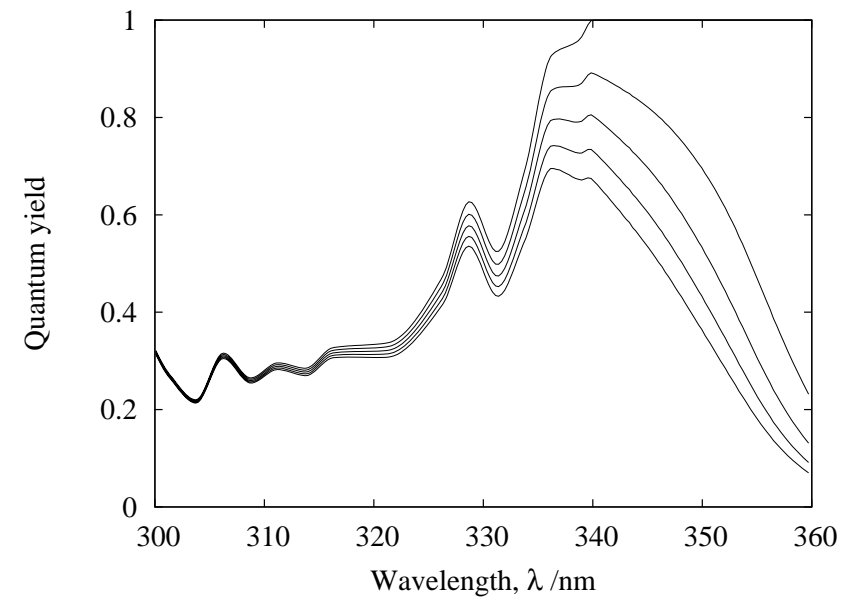

Fig. 5. Molecular channel quantum yield for different pressures. From highest to lowest the lines represent pressures of 0, 250, 500, 750 and 1000 mbar.

isotope effect. The same trend is not seen for $\mathrm{D}_{2} \mathrm{CO}$. The kinetic isotope effects for $\mathrm{HDCO}$ and $\mathrm{D}_{2} \mathrm{CO}$ do not converge to 1 as the pressure goes towards 0 mbar because each isotopologue has a unique absorption cross section (Gratien et al., 2007). The two heavier isotopologues have photoexcitation rates slightly higher than $\mathrm{H}_{2} \mathrm{CO}$.

Figure 5 shows the significant variation in the quantum yield within the pressure range of the present work. At the lowest pressure the yield is one at wavelengths above the radical channel threshold. As the pressure increases the yield rapidly decreases.

The RRKM model assumes that competition between unimolecular decomposition on the $S_{0}$ surface and collisional relaxation is the mechanism governing the observed isotope effects. Isotopic substitution results in lower vibrational frequencies and a higher density of states, leading to a longer lifetime via Eq. 4. Comparing the calculated results (lines) with experiments (symbols) in Fig. 4, it is seen that straightforward application of RRKM theory is not sufficient to explain the experimental observations. It is therefore likely to be working in concert with other processes; the remaining isotope effect could for example be explained by an additional reservoir of population. However, while other isomers of formaldehyde exist, they are higher in energy and are therefore not highly populated. It therefore seems more likely that the remaining isotope effect originates from the rate of the non-radiative transition from $S_{1}$ to $S_{0}$, which is not considered in the present model. This conclusion agrees with the results of a study by Simonsen et al. (2008). Based on a femtosecond dynamics experiment and an ab initio study of the excited states, they conclude that the large ${ }^{13} \mathrm{C},{ }^{18} \mathrm{O}$ and $\mathrm{D}$ isotope effects occuring in formaldehyde photolysis (Feilberg et al., 2005b, 2007b; Nilsson et al., 2010) are due to the isotope induced differences in the intersurface coupling terms.

\section{Conclusions}

The pressure dependence in the photolysis of $\mathrm{D}_{2} \mathrm{CO}$ has been investigated for the first time. The result at atmospheric pressure is in agreement with data from two previous determinations at another experimental facility, and the overall trend in pressure dependence is analogous to what was recently determined for the HDCO isotopologue. The experimental trend in pressure dependence can be partially explained by RRKM calculations for both mono- and dideutero formaldehyde, indicating that part of the pressure dependence is a result of competition between unimolecular dissociation and collisional relaxation. The full magnitude of the isotope effect is not reproduced by the calculations and we propose that there are other processes contributing to the isotope effects.

The present work and the previous publication on HDCO (Nilsson et al., 2010) show that the altitude dependent isotopic fractionation suggested by Röckmann et al. (2003); Mar et al. (2007); Pieterse et al. (2011) likely is a result of pressure dependence. It is important to be able to use this to constrain the isotopic budget to give a better quantitative determination of the isotope effect. Due to the overlap between the product channels design of experiments that enable investigation of one channel is a significant challenge. The results presented here can be used to quantify the pressure dependence of deuterium isotopic fractionation once the question of the radical channel quantum yield is resolved; currently available estimates conflict. Accurate description of the underlying mechanism is the key to interpreting the observations and improving trace gas budgets and descriptions of in situ chemistry.

As shown in Table 1, the available experimental laboratory (Nilsson et al., 2010; Rhee et al., 2008) and environmental chamber results (Feilberg et al., 2007b; Röckmann et al., 2010) for the isotope effect in HDCO photolysis are in reasonable agreement, with the exception of the work by Rhee et al. (2008). The work by Rhee et al. (2008) may suffer from errors as a result of surface reactions in the small reaction vessels used in that study. The problem of keeping a stable concentration of formaldehyde in the gas phase, due to for example adsorption or polymerisation, is likely to play a greater role in a small reaction vessel.

Future work should consider the pressure dependence of the photolytic isotope effect for ${ }^{13} \mathrm{C}$ and ${ }^{18} \mathrm{O}$ substituted formaldehyde, which will clearly impact the seasonal variation in the isotopic composition of tropospheric CO (Röckmann et al., 2002). Another interesting study would be to investigate the influence of bath gas composition. Experiments using a polyatomic bath gas that is more efficient at quenching excitation would make it possible to see the leveling off of the $\mathrm{D}_{2} \mathrm{CO}$ curve, as is seen for HDCO in Fig. 4.

In conclusion, only part of the pressure dependence in the photolytic deuterium fractionation in formaldehyde photolysis is due to the longer unimolecular lifetime of the heavy isotopologues. The simplistic single electronic state 
RRKM model considered in this study does not describe the entire photolysis process (from excitation to dissociation) and cannot quantitatively describe the isotopic fractionation. Full chemical dynamics calculations considering both the $S_{0}$ and $S_{1}$ surface will be useful in further quantifying the isotopic fractionation in formaldehyde photolysis and unraveling its origin. In addition, it would be very useful to characterize isotopic fractionation occuring on the $S_{0}$ surface in both the traditional and in the roaming atom pathways using a trajectory calculation; to date these calculations have only been performed for the main formaldehyde isotopologue (Townsend et al., 2004; Lahankar et al., 2007; Bowman and Suits, 2011).

\section{Supplementary material related to this article is available online at http://www.atmos-chem-phys.net/14/ 551/2014/acp-14-551-2014-supplement.pdf.}

Acknowledgements. We thank Vibeke F. Andersen for help with the experiments and Markku Räsänen and Leonid Khraitschev at the University of Helsinki for sharing a sample of the dideutero formaldehyde isotopologue. We thank J. M. Olsen, C. Steinmann and A. S. Christensen for granting us access to their SUNRAY computer cluster.

Edited by: T. Röckmann

\section{References}

Atkinson, R., Baulch, D. L., Cox, R. A., Crowley, J. N., Hampson, R. F., Hynes, R. G., Jenkin, M. E., Rossi, M. J., Troe, J., and Subcommittee, I.: Evaluated kinetic and photochemical data for atmospheric chemistry: Volume II; gas phase reactions of organic species, Atmos. Chem. Phys., 6, 3625-4055, doi:10.5194/acp-63625-2006, 2006.

Batenburg, A. M., Schuck, T. J., Baker, A. K., Zahn, A., Brenninkmeijer, C. A. M., and Röckmann, T.: The stable isotopic composition of molecular hydrogen in the tropopause region probed by the CARIBIC aircraft, Atmos. Chem. Phys., 12, 46334646, doi:10.5194/acp-12-4633-2012, 2012.

Billing, G. D. and Mikkelsen, K. V.: Introduction to Molecular Dynamics and Chemical Kinetics, Wiley-Interscience Publication, 45-49, 1996.

Bowman, J. M. and Suits, A. G.: Roaming reactions: The third way, Phys. Today, 64, 33-37, 2011.

Bowman, J. M. and Zhang, X.: New insights on reaction dynamics from formaldehyde photodissociation, Phys. Chem. Chem. Phys., 8, 321-332, doi:10.1039/B512847C, 2006.

Brenninkmeijer, C. A. M., Janssen, C., Kaiser, J., Röckmann, T., Rhee, T. S., and Assonov, S. S.: Isotope Effects in the Chemistry of Atmospheric Trace Compounds, Chem. Rev., 103, 51255162, doi:10.1021/cr020644k, 2003.

Deegan, M. J. O. and Knowles, P. J.: Perturbative corrections to account for triple excitations in closed and open shell coupled cluster theories, Chem. Phys. Lett., 227, 321-326, doi:10.1016/00092614(94)00815-9, 1994.
Dunning, T. H. J.: Gaussian basis sets for use in correlated molecular calculations. I. The atoms boron through neon and hydrogen, J. Chem. Phys., 90, 1007-1023, doi:10.1063/1.456153, 1989.

Ehhalt, D. H. and Rohrer, F.: The tropospheric cycle of $\mathrm{H}_{2}$ : a critical review, Tellus B, 61, 500-535, doi:10.1111/j.16000889.2009.00416.x, 2009.

Feilberg, K., Griffith, D., Johnson, M., and Nielsen, C.: The ${ }^{13} \mathrm{C}$ and $\mathrm{D}$ kinetic isotope effects in the reaction of $\mathrm{CH}_{4}$ with $\mathrm{Cl}$, Int. J. Chem. Kinet., 37, 110-118, 2005a.

Feilberg, K. L., D’Anna, B., Johnson, M. S., and Nielsen, C. J.: Relative Tropospheric Photolysis Rates of HCHO, $\mathrm{H}^{13} \mathrm{CHO}, \mathrm{HCH}^{18} \mathrm{O}$, and DCDO Measured at the European Photoreactor Facility, J. Phys. Chem. A, 109, 8314-8319, doi:10.1021/jp0513723, 2005b.

Feilberg, K. L., D’Anna, B., Johnson, M. S., and Nielsen, C. J.: Relative Tropospheric Photolysis Rates of HCHO, $\mathrm{H}^{13} \mathrm{CHO}, \mathrm{HCH}^{18} \mathrm{O}$, and DCDO Measured at the European Photoreactor Facility, J. Phys. Chem. A, 111, 992-992, doi:10.1021/jp068794c, 2007a.

Feilberg, K. L., Johnson, M. S., Bacak, A., Rockmann, T., and Nielsen, C. J.: Relative tropospheric photolysis rates of HCHO and HCDO measured at the European photoreactor facility, J. Phys. Chem. A, 111, 9034-9046, 2007b.

Gerst, S. and Quay, P.: Deuterium component of the global molecular hydrogen cycle, J. Geophys. Res., 106, 5021, doi:10.1029/2000JD900593, 2001.

Gratien, A., Nilsson, E., Doussin, J.-F., Johnson, M. S., Nielsen, C. J., Stenstrøm, Y., and Picquet-Varrault, B.: UV and IR Absorption Cross-sections of HCHO, HCDO, and DCDO, J. Phys. Chem. A, 111, 11506-11513, doi:10.1021/jp074288r, 2007.

Gray, S., Miller, W., Yamaguchi, Y., and Schaefer, H.: J. Am. Chem. Soc., 103, 1900-1904, 1981.

Griffith, D. W.: Synthetic Calibration and Quantitative Analysis of Gas-Phase FT-IR Spectra, Appl. Spectrosc., 50, 59-70, doi:10.1366/0003702963906627, 1996.

Halkier, A., Helgaker, T., Jørgensen, P., Klopper, W., Koch, H., Olsen, J., and Wilson, A. K.: Basis-set convergence in correlated calculations on $\mathrm{Ne}, \mathrm{N}_{2}$, and $\mathrm{H}_{2} \mathrm{O}$, Chem. Phys. Lett., 286, 243 252, doi:10.1016/S0009-2614(98)00111-0, 1998.

Herath, N. and Suits, A.: Roaming radical reactions, Phys. Chem. Let., 2, 642-647, 2011.

Hu, H., Dibble, T., Tyndall, G., and Orlando, J.: TemperatureDependent Branching Ratios of Deuterated Methoxy Radicals (CH2DO>) Reacting With $\mathrm{O}_{2}$, J. Phys. Chem. A, 116, 62956302, 2012.

Johnson, M. S., Feilberg, K. L., and von Hessberg, Nielsen, O. J.: Isotope effects in atmospheric processes, Chem. Soc. Rev., 31, 313-323, 2002.

Knowles, P. J., Hampel, C., and Werner, H.-J.: Coupled cluster theory for high spin, open shell reference wave functions, J. Chem. Phys., 99, 5219-5227, doi:10.1063/1.465990, 1993.

Knowles, P. J., Hampel, C., and Werner, H.-J.: Erratum: "Coupled cluster theory for high spin, open shell reference wave functions" [ J. Chem. Phys. 99, 5219 (1993)], J. Chem. Phys., 112, 31063107, doi:10.1063/1.480886, 2000.

Krol, M., Houweling, S., Bregman, B., van den Broek, M., Segers, A., van Velthoven, P., Peters, W., Dentener, F., and Bergamaschi, P.: The two-way nested global chemistry-transport zoom model 
TM5: algorithm and applications, Atmos. Chem. Phys., 5, 417432, doi:10.5194/acp-5-417-2005, 2005.

Lahankar, S. A., Chambreau, S. D., Zhang, X., Bowman, J. M., and Suits, A. G.: Energy dependence of the roaming atom pathway in formaldehyde decomposition, J. Chem. Phys., 126, 44314 44 314, 2007.

Mar, K. A., McCarthy, M. C., Connell, P., and Boering, K. A.: Modeling the photochemical origins of the extreme deuterium enrichment in stratospheric $\mathrm{H}_{2}$, J. Geophys. Res., 112, D19302, doi:10.1029/2006JD007403, 2007.

Miller, W.: Tunneling corrections to unimolecular rate constants, with application to formaldehyde, J. Am. Chem. Soc., 101, 6810-6814, 1979.

Nilsson, E. J. K., Johnson, M. S., Taketani, F., Matsumi, Y., Hurley, M. D., and Wallington, T. J.: Atmospheric deuterium fractionation: $\mathrm{HCHO}$ and $\mathrm{HCDO}$ yields in the $\mathrm{CH}_{2} \mathrm{DO}+\mathrm{O}_{2}$ reaction, Atmos. Chem. Phys., 7, 5873-5881, doi:10.5194/acp-7-5873-2007, 2007

Nilsson, E. J. K., Bache-Andreassen, L., Johnson, M. S., and Nielsen, C. J.: Relative Tropospheric Photolysis Rates of Acetaldehyde and Formaldehyde Isotopologues Measured at the European Photoreactor Facility, J. Phys. Chem. A, 113, 34983504, doi:10.1021/jp811113c, 2009a.

Nilsson, E. J. K., Eskebjerg, C., and Johnson, M. S.: A photochemical reactor for studies of atmospheric chemistry, Atmos. Env., 43, 3029-3033, doi:10.1016/j.atmosenv.2009.02.034, 2009b.

Nilsson, E. J. K., Andersen, V. F., Skov, H., and Johnson, M. S.: Pressure dependence of the deuterium isotope effect in the photolysis of formaldehyde by ultraviolet light, Atmos. Chem. Phys., 10, 3455-3462, doi:10.5194/acp-10-3455-2010, 2010.

Pieterse, G., Krol, M. C., Batenburg, A. M., Steele, L. P., Krummel, P. B., Langenfelds, R. L., and Röckmann, T.: Global modelling of $\mathrm{H}_{2}$ mixing ratios and isotopic compositions with the TM5 model, Atmos. Chem. Phys., 11, 7001-7026, doi:10.5194/acp-11-70012011, 2011.

Rhee, T. S., Brenninkmeijer, C. A. M., and Röckmann, T.: Hydrogen isotope fractionation in the photolysis of formaldehyde, Atmos. Chem. Phys., 8, 1353-1366, 2008,

http://www.atmos-chem-phys.net/8/1353/2008/.

Röckmann, T., Jöckel, P., Gros, V., Bräunlich, M., Possnert, G., and Brenninkmeijer, C. A. M.: Using ${ }^{14} \mathrm{C},{ }^{13} \mathrm{C},{ }^{18} \mathrm{O}$ and ${ }^{17} \mathrm{O}$ isotopic variations to provide insights into the high northern latitude surface CO inventory, Atmos. Chem. Phys., 2, 147-159, doi:10.5194/acp-2-147-2002, 2002.

Röckmann, T., Rhee, T. S., and Engel, A.: Heavy hydrogen in the stratosphere, Atmos. Chem. Phys., 3, 2015-2023, doi:10.5194/acp-3-2015-2003, 2003.

Röckmann, T., Walter, S., Bohn, B., Wegener, R., Spahn, H., Brauers, T., Tillmann, R., Schlosser, E., Koppmann, R., and Rohrer, F.: Isotope effect in the formation of $\mathrm{H}_{2}$ from $\mathrm{H}_{2} \mathrm{CO}$ studied at the atmospheric simulation chamber SAPHIR, Atmos. Chem. Phys., 10, 5343-5357, doi:10.5194/acp-10-53432010, 2010.
Rothman, L. S., Gordon, I. E., Barbe, A., Benner, D. C., Bernath, P. E., Birk, M., Boudon, V., Brown, L. R., Campargue, A., Champion, J. P., Chance, K., Coudert, L. H., Dana, V., Devi, V. M., Fally, S., Flaud, J. M., Gamache, R. R., Goldman, A., Jacquemart, D., Kleiner, I., Lacome, N., Lafferty, W. J., Mandin, J. Y., Massie, S. T., Mikhailenko, S. N., Miller, C. E., Moazzen-Ahmadi, N., Naumenko, O. V., Nikitin, A. V., Orphal, J., Perevalov, V. I., Perrin, A., Predoi-Cross, A., Rinsland, C. P., Rotger, M., Simeckova, M., Smith, M. A. H., Sung, K., Tashkun, S. A., Tennyson, J., Toth, R. A., Vandaele, A. C., and Vander Auwera, J.: The HITRAN 2008 molecular spectroscopic database, J. Quant. Spectrosc. Ra., 110, 533-572, 2009.

Sander, S. P., Golden, D. M., Kurylo, M. J., Moortgat, G. K., Wine, P. H., Ravishankara, A. R., Kolb, C. E., Molina, M. J., FinlaysonPitts, B. J., Huie, R. E., and Orkin, V. L.: Chemical Kinetics and Photochemical Data for Use in Atmospheric Studies. Evaluation Number 15, National Aeronautics and Space Administration, Jet Propulsion Laboratory, California Institute of Technology, Pasadena, California, USA, JPL Publication 06-2, 2006.

Schmidt, J. A., Johnson, M. S., Jung, Y., Danielache, S. O., Hattori, S., and Yoshida, N.: Predictions of the sulfur and carbon isotope effects in the $\mathrm{OH}+\mathrm{OCS}$ reaction, Chem. Phys. Let., 531, 64-69, doi:10.1016/j.cplett.2012.02.049, 2012.

Seinfeld, J. and Pandis, S.: From air pollution to climate change, Atmospheric Chemistry and Physics, John Wiley \& Sons, New York, 1326, 1998.

Simonsen, J., Rusteika, N., Johnson, M. S., and Sølling, T. I.: Atmospheric photochemical loss of $H$ and $H_{2}$ from formaldehyde: the relevance of ultrafast processes, Phys. Chem. Chem. Phys., 10, 674-680, 2008.

Stein, S. E. and Rabinovitch, B. S.: Accurate evaluation of internal energy level sums and densities including anharmonic oscillators and hindered rotors, J. Chem. Phys., 58, 2438-2445, doi:10.1063/1.1679522, 1973.

Townsend, D., Lahankar, S. A., Lee, S. K., Chambreau, S. D., Suits, A. G., Zhang, X., Rheinecker, J., Harding, L. B., and Bowman, J. M.: The Roaming Atom: Straying from the Reaction Path in Formaldehyde Decomposition, Science, 306, 1158-1161, doi:10.1126/science.1104386, 2004.

Troe, J.: Analysis of Quantum Yields for the Photolysis of Formaldehyde at $>310 \mathrm{~nm}$, J. Phys. Chem. A, 111, 3868-3874, doi:10.1021/jp066886w, 2007.

Wardlaw, D. M. and Marcus, R. A.: Adv. Chem. Phys., 70, 231-263, doi:10.1002/9780470141199.ch7, 1988.

Watts, J. D., Gauss, J., and Bartlett, R. J.: Coupled-cluster methods with noniterative triple excitations for restricted open-shell Hartree-Fock and other general single determinant reference functions. Energies and analytical gradients, J. Chem. Phys., 98, 8718-8733, doi:10.1063/1.464480, 1993.

Woon, D. E. and Dunning, T. H. J.: Gaussian basis sets for use in correlated molecular calculations. III. The atoms aluminum through argon, J. Chem. Phys., 98, 1358-1371, doi:10.1063/1.464303, 1993. 